\title{
The economic impact of infection with Eimeria spp. in broiler farms from Romania
}

\author{
Adriana Györke , Zsuzsa Kalmár¹, Loredana Maria Pop¹, Ovidiu Loan Şuteu² \\ ${ }^{1}$ University of Agricultural Science and Veterinary Medicine Cluj-Napoca, Faculty of Veterinary Medicine, Parasitology and Parasitic Diseases \\ Department, Cluj-Napoca, Romania. \\ ${ }^{2}$ Ceva Sante Animale Romania, Bucureşti, Romania.
}

\begin{abstract}
A survey was conducted on chicken broiler farms from Romania in August-November 2010 to evaluate economic losses due to coccidiosis. Data were collected from six broiler farms of different capacity regarding chemoprophylaxis program, weight gain, feed conversion, and mortality, for two previous flocks in two houses of each farm, and finally we evaluated the economic losses. Also, faeces samples were collected and oocysts were classified according to their size, and virulence of each Eimeria spp. field isolate was determined by lesion scoring. Correlations between economic performance, oocysts category, and virulence of Eimeria were assessed by multiple linear regression. Total economic losses per 24 flocks of 18,000 chicks each were about $€ 37,948.2$, with an average of $€ 3,162.4$ per flock, and they were caused by mortality (34.8\%) and poor feed conversion (65.2\%). Poor body weight gain was associated with AM oocyst category (presumptively E. acervulina and/or E. mitis), high lesion score in the duodenum, and coccidiostat used for chemoprophylaxis. Feed conversion ratio was linked to the same parameters as body weight gain, minus chemoprophylaxis programme, plus total lesion score. The percentage of mortality was influenced by the lesion score in the caecum and total lesion score. Statistical analysis showed that epidemiological survey of broiler flocks during the grower period can help the farmer to avoid important economic losses due to coccidiosis. As in other countries, the economic losses caused by coccidiosis in Romania are important, and a good prophylaxis programme can reduce the economic impact of coccidiosis.
\end{abstract}

Key Words: body weight gain, chickens, feed conversion ratio, losses

\section{Introduction}

Coccidiosis is the most common and costly disease of the poultry industry, caused by apicomplexan parasites belonging to the genus Eimeria that develop in the epithelial cells of the gut. Seven species of Eimeria are widely recognized to infect chickens: E. acervulina, E. mitis, E. necatrix, E. tenella, E. praecox, E. maxima, and E. brunetti (Shirley, 1986). Based on epidemiological studies from the latest years, in broiler chickens, $E$. acervulina, E. tenella, E. maxima, and E. praecox are frequently found, and more rarely, E. mitis and E. necatrix (Haug et al., 2008a; Sun et al., 2009; Hamidinejat et al., 2010; Ogedengbe et al., 2011).

The poultry industry cannot be viable without specific prophylaxis based mainly on the use of in-feed anticoccidial drugs named coccidiostats (Peek and Landman, 2011) and

\footnotetext{
Received October 21, 2015 and accepted March 15, 2016 Corresponding author: adriana.gyorke@usamvcluj.ro http://dx.doi.org/10.1590/S1806-92902016000500010
}

Copyright (C) 2016 Sociedade Brasileira de Zootecnia. This is an Open Access article distributed under the terms of the Creative Commons Attribution License (http://creativecommons.org/licenses/by/4.0/), which permits unrestricted use, distribution, and reproduction in any medium, provided the original work is properly cited. rarely on vaccination (live vaccines), because of economic reasons and adverse effects on early chick growth (Williams, 2002). According to the European Commission (report COM 2008/233 of Regulation 1831/2003), in 2006 in Europe, approximately $84 \%$ of broilers were prevented with coccidiostats and $12 \%$ by vaccination. In Romania, prevention of coccidiosis on broiler farms is based on coccidiostats and vaccination (mainly Paracox-8), used partially only in layers and breeders (personal observation). Nowadays, in Europe, 12 commercial products containing chemicals and ionophores are accepted. Their extensive use led to development of drug resistance (Chapman, 1997), which was described globally for all anticoccidial drugs and for all Eimeria species (Kawazoe and Fabio, 1994; Peeters et al., 1994; Stephen et al., 1997; Peek and Landman, 2003; Williams, 2006; Abbas et al., 2008; Zhang et al., 2013). However, coccidiosis did not occur on farms with drug-resistant strains of Eimeria (Hemsley, 1964), which cause subclinical coccidiosis expressed by poor weight gain and high feed consumption (Harfoush et al., 2010; Jenkins et al., 2010), leading to considerable economic losses. Annual costs of coccidiosis in the world have been estimated at two billion euro (Peek and Landman, 2011). 
As there are not many published studies about estimates for economic losses due to coccidiosis, we conducted a survey on chicken broiler farms from Romania in AugustNovember 2010 aiming to record performance and to evaluate their impact on the economic losses. In addition, the correlation between performance and virulence of Eimeria isolates was assessed.

\section{Material and Methods}

The Union of Poultry Breeders from Romania (UCPR) has 276 members, comprising 18 large (produce over 10 thousand tonnes of meat/year), 22 medium (produce between 5-10 thousand tonnes of meat/year), and 236 small (produce less than 5 thousand tonnes of meat/year) poultry companies. The production of poultry meat in 2010 was about 317 thousand tonnes. Average performances in the same year were: daily body weight gain, $54.19 \mathrm{~g}$; feed conversion ratio, 1.859; mortality, 4.24\%; and European Production Index, 299.15 (data from the official web page of UCPR). The most common broiler breeds are Cobb500 and Ross308, and they are reared in houses made of concrete, on wood shavings.

Chemoprophylaxis of coccidiosis, on the farms included in the study, was performed with lasalocid (4/6 farms), narasin/nicarbazin (1/6 farms), monensin (1/6 farms), and diclazuril (2/6 farms) (Table 2). In all cases, the farmers used the full program. Four farms ("A", "F", "J", and "K") out of six used the same coccidiostat for both flocks in a house. Otherwise, small-size farms used ionophores (lasalocid) for chemoprophylaxis; mediumsize farms used ionophores (lasalocid, monensin), chemicals (diclazuril), and a combination of them (narasin + nicarbazin); while large-size farms used only chemicals (diclazuril) (Tables 2 and 3).

The average age at slaughter is about 42 days, and average live weight is $2.2 \mathrm{~kg}$. The time between successive grow-outs is about 2-3 weeks. Used litter is removed and the broiler houses are cleaned and chemically disinfected.

During August-November 2010, 12 farms were sampled by simple random sample picking (confidence interval of 5.45) for anticoccidial sensitivity test (Figure 1). Among these farms, six answered a questionnaire and were included in the present paper. Because only half of farmers filled the questionnaire, the confidence interval increased from 5.45 to 7.85 (confidence level of $95.0 \%$ ). Farms were subsequently divided according to their capacity into three groups: small $(\mathrm{n}=3)$, medium $(\mathrm{n}=2)$, and large $(\mathrm{n}=1)$. The capacities of these farms are ranged between $9 \times 10^{5}-2.3$ thousand chickens/year and they do not have their own feed mills.

A questionnaire was formulated to record data about coccidiostats used on those farms, chemoprophylaxis program, weight gain, feed conversion, and mortality for two previous flocks (cycles) in two separate houses of each farm.

Economic losses were estimated due to poor body weight gain, feed conversion ratio, and mortality for flocks investigated following the model developed by Williams (1999). For this purpose, we assumed some parameters presented in Table 1. These losses were calculated for values that exceed the national average regarding mortality, body weight gain, and feed conversion ratio in broilers (Table 1). Costs were expressed in euro.

Estimates for cost of anticoccidial therapy were not possible because the farmers reported no outbreaks of coccidiosis or any treatment for coccidiosis. The cost of anticoccidial prophylaxis was comprised in the cost of feed.

Table 1 - Assumed parameters for estimation of economic losses

\begin{tabular}{lcc}
\hline Parameter & Mean & Source \\
\hline Length of life & 42 days & Farmers \\
Value of day-old chickens & 2.1 RON $\left(0.50 \mathrm{E}^{1}\right)$ & $\mathrm{UCPR}^{2}$ \\
Value of dressed broiler meat/kg & $7.36 \mathrm{RON}(1.75 \mathrm{E})$ & $\mathrm{UCPR}$ \\
Value of 42 -day-old chicken/kg & $5.18 \mathrm{RON}(1.23 \mathrm{E})$ & $\mathrm{UCPR}$ \\
Cost of feed/kg & $1.6 \mathrm{RON}(0.38 \mathrm{E})$ & $\mathrm{UCPR}$ \\
(including the cost of coccidiostats) & & \\
Mortality (\%) & 4.24 & $\mathrm{UCPR}$ \\
Number of chicks/flock & 18,000 & Farmers \\
Body weight gain (g/day) & 54.19 & $\mathrm{UCPR}$ \\
Body weight at slaughter $(\mathrm{kg})$ & 2.2 & Farmers \\
Feed conversion ratio & 1.859 & UCPR \\
Overhead costs & $15 \%$ & Williams $(1999)$ \\
\hline
\end{tabular}

${ }^{1} 1 \mathrm{E}=4,2099$ RON (average for 2010).

${ }^{2}$ Union of Poultry Breeders from Romania.

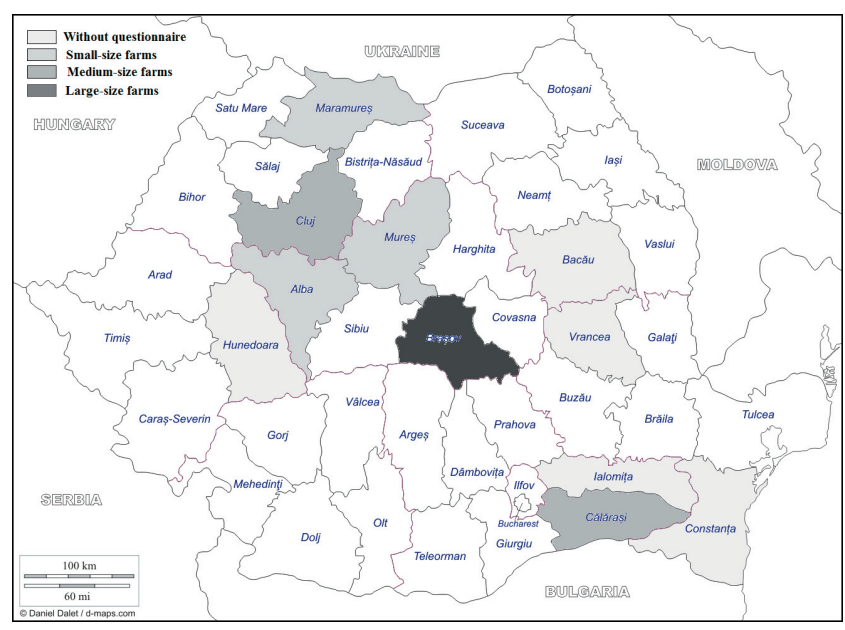

Figure 1 - Location of the farms where the data were collected. 
Table 2 - Performance, prophylaxis of coccidiosis, oocyst categories, and virulence of Eimeria isolates on investigated broiler farms during August-November 2010 in Romania

\begin{tabular}{|c|c|c|c|c|c|c|c|c|c|c|c|c|c|c|c|c|}
\hline \multirow[t]{2}{*}{ Farm } & \multirow[t]{2}{*}{ House } & \multicolumn{2}{|c|}{$\begin{array}{l}\text { Body weight } \\
\text { gain }(\mathrm{g})\end{array}$} & \multicolumn{2}{|c|}{$\begin{array}{c}\text { Feed conversion } \\
\text { ratio }\end{array}$} & \multicolumn{2}{|c|}{ Mortality (\%) } & \multicolumn{2}{|c|}{$\begin{array}{l}\text { Coccidiosis } \\
\text { prophylaxis }\end{array}$} & \multicolumn{3}{|c|}{ Length category (\%) } & \multicolumn{4}{|c|}{ Lesion score } \\
\hline & & F1 & $\mathrm{F} 2$ & F1 & $\mathrm{F} 2$ & F1 & $\mathrm{F} 2$ & F1 & $\mathrm{F} 2$ & $\mathrm{AM}$ & NTP & $\mathrm{BM}$ & $\mathrm{D}$ & $\mathrm{J}$ & $\mathrm{C}$ & Total \\
\hline \multicolumn{17}{|c|}{ Small-size farms } \\
\hline \multirow[t]{2}{*}{ A } & 1 & 49.3 & 48.3 & 2.1 & 2.4 & 6.4 & 11.9 & Las & Las & 34.8 & 43.5 & 21.7 & 4.0 & 0.0 & 2.1 & 6.1 \\
\hline & 2 & 47.0 & 42.3 & 2.2 & 2.3 & 10.0 & 6.9 & Las & Las & 34.6 & 50.0 & 15.4 & 3.3 & 0.1 & 2.0 & 5.4 \\
\hline $\mathrm{F}$ & 1 & 57.5 & 57.5 & 1.8 & 1.8 & 3.8 & 3.4 & Las & Las & 52.8 & 44.4 & 2.8 & 1.7 & 0.1 & 1.7 & 3.5 \\
\hline K & 2 & 55.0 & 51.8 & 2.0 & 2.0 & 4.7 & 5.6 & Las & Las & 37.5 & 61.1 & 1.4 & 0.4 & 0.0 & 0.0 & 0.4 \\
\hline \multicolumn{17}{|c|}{ Medium-size farms } \\
\hline \multirow[t]{2}{*}{$\mathrm{C}$} & 1 & 62.4 & 62.1 & 1.7 & 1.7 & 2.5 & 2.9 & $\mathrm{Nar} / \mathrm{Nic}$ & Dicl & 87.5 & 12.5 & 0 & 1.4 & 0.0 & 0.1 & 1.5 \\
\hline & 2 & 59.2 & 59.3 & 1.8 & 1.8 & 2.8 & 3.2 & Nar/Nic & Dicl & nd & nd & nd & 1.3 & 0.3 & 0.1 & 1.7 \\
\hline G & 1 & 56.1 & 49.2 & 1.6 & 2.1 & 2.9 & 5.1 & Mon & Las & 40.0 & 40.0 & 20.0 & 0.0 & 0.2 & 0.0 & 0.2 \\
\hline J & 2 & 52.4 & 55.0 & 2.0 & 2.1 & 6.6 & 8.6 & Dicl & Dicl & 48.8 & 43.9 & 2.3 & 0.7 & 0.8 & 0.0 & 1.5 \\
\hline \multicolumn{2}{|c|}{$\begin{array}{l}\text { Average in } \\
2010^{1}\end{array}$} & 54.19 & & 1.859 & & 4.24 & & & & & & & & & & \\
\hline
\end{tabular}

F - flock; AM - E. acervulina and/or E. mitis; NTP - E. necatrix, E. tenella, and/or E. praecox; BM - E. brunetti and/or E. maxima; D - duodenum; J - jejunum; C - caecum. Las - lasalocid; Nar - narasin; Nic - nicarbazin; Dicl - diclazuril; Mon - monensin; nd - not done.

${ }^{1}$ Data from the Union of Poultry Breeders from Romania.

Table 3 - Average and range of evaluated parameters by farm capacity

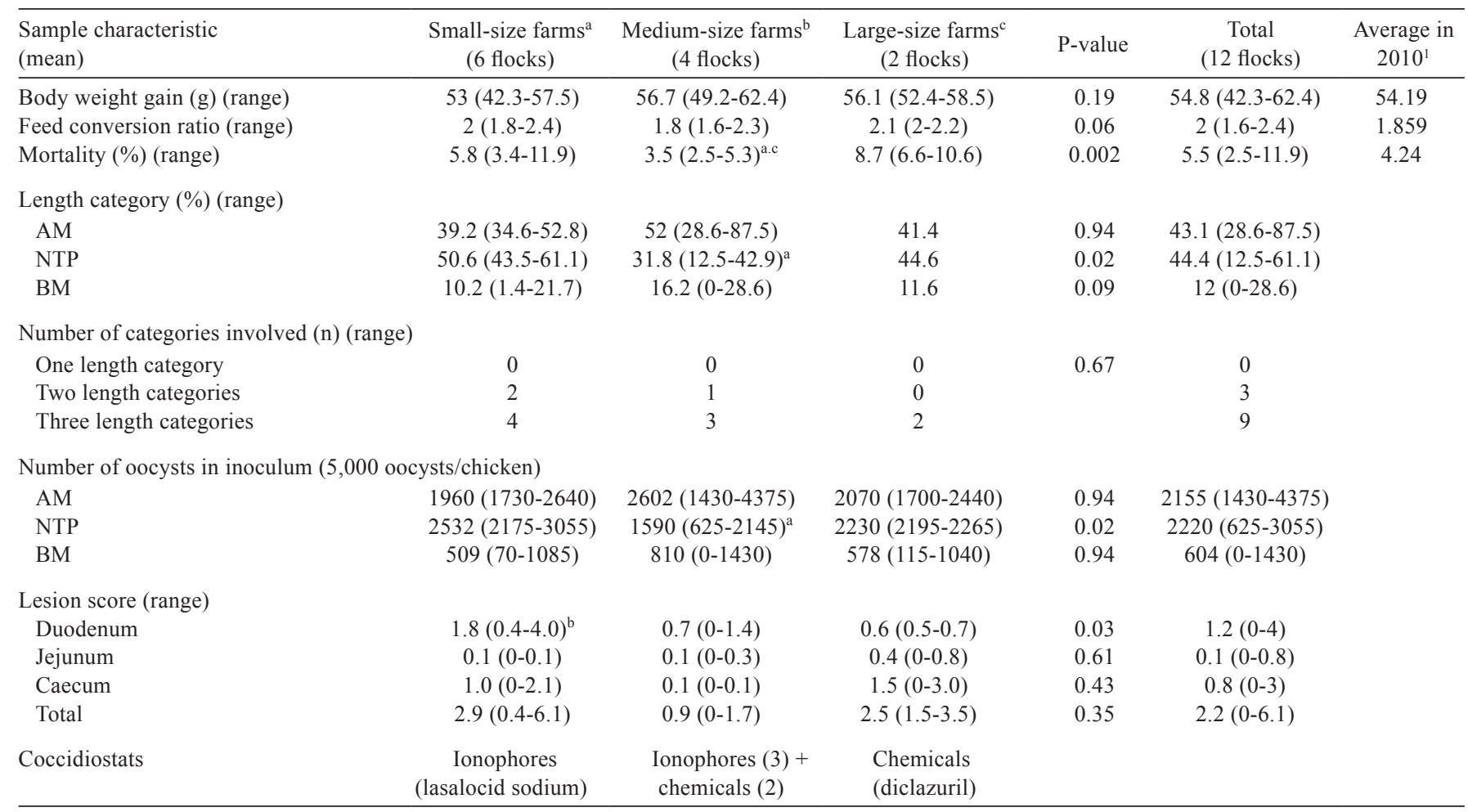

AM - E. acervulina and/or E. mitis; NTP - E. necatrix, E. tenella, and/or E. praecox; BM - E. brunetti, and/or E. maxima.

a,b,c - t-test $\mathrm{P} \leq 0.05$.

${ }^{1}$ Union of Poultry Breeders from Romania. 
The total loss due to mortality is the sum of equations (1) and (2).

LM (loss due to mortality) $=\mathrm{N}$ (no. of chickens dead) $\times$ [VC (value of day-old chick) + CCF (cost of cumulative feed consumed by a single bird in 21 days $=43.8 \%$ from total) + OC (overhead cost)]

PP $($ potential profit $)=[\mathrm{N} \times \mathrm{ML}$ (mean live weight of chickens) $\times \mathrm{SP}$ (selling price per $\mathrm{kg}$ of live chickens at processing plant $)]-[\mathrm{N} \times(\mathrm{TRC}$ (total rearing cost of a chicken) - VC)]

Losses due to decreased body weight gain:

TSP $($ total selling price $)=(\mathrm{N} \times \mathrm{ML} \times \mathrm{SP})$

Losses due to increased feed conversion ratio:

TCF (total cost of feed) $=\mathrm{L}$ (tonnes of live weight) $\times$ $\mathrm{FCR} \times \mathrm{CF}$ (cost of feed per tonne)

Also, faeces samples (12, in total) were collected from two flocks per farm, when chickens were 20-35 days old (median 28 days). Approximately $250 \mathrm{~g}$ of fresh faecal droppings/sample were collected along the feed and water lines. The samples were processed once they arrived in the laboratory by flotation and McMaster (number of oocysts per gram of faeces $=\mathrm{OPG}$ ) methods with saturated sodium chloride (specific gravity 1.18-1.2) and stored at $4{ }^{\circ} \mathrm{C}$ until the next day. Afterwards, oocysts were isolated, purified, and concentrated from faeces with saturated salt solution (Shirley, 1995) and sporulated in $2.5 \%$ potassium dichromate solution. The oocysts were washed free from the salt and potassium dichromate by repeated centrifugation and resuspended in tap water. After sporulation, oocysts were classified according to their size (Haug et al., 2008b), and virulence of each Eimeria spp. field isolate was assessed by lesion scoring (Johnson and Reid, 1970) following experimental infection.

Oocysts in each sample were classified according to the protocol described by Haug et al. (2008b). Briefly, 50 oocysts from each sample were measured with CELL-F software using digital photographs (camera Olympus ODP72) taken with an Olympus BX61 microscope at 400x magnification (Long and Reid, 1982). Oocysts were categorized into three groups: AM group - small oocysts $18.8 \mu \mathrm{m}$ long (presumptively E. acervulina and/or $E$. mitis); NTP group - medium-sized oocysts 18.9 to $23.8 \mu \mathrm{m}$ long (presumptively E. necatrix, E. tenella, and/or E. praecox); and BM group - large oocysts, longer than $23.9 \mu \mathrm{m}$ (presumptively E. brunetti and/or E. maxima).

To evaluate the virulence of Eimeria spp. field isolates, 130 one-day-old broiler chicks (Ross 308) were obtained from a hatchery (Bihor county) and reared as a single group from 1 to 14 days of age, when chicks were randomly divided into 13 groups of 10 birds each, in cages, as negative control and 12 experimental groups, challenged with Eimeria isolates from the farms (two isolates per farm). Experimental infection was performed at 14 days old with 5,000 oocysts/isolate. Virulence of Eimeria filed isolates was evaluated by lesion score at six days post-challenge using a score of $0-4$ according to Johnson and Reid (1970). Diet formulas contained no anticoccidial feed additives. Chicks were offered feed and water ad libitum, and were exposed to continuous light.

Differences in mortality rate, body weight gain, feed conversion ratio, oocyst categories, and lesion score between farms according to their capacity were evaluated by one-way analysis of variance (ANOVA) (GraphPad software) and a P-value of $<0.05$ was statistically significant. In addition, correlations between economic performance, oocyst category, and virulence of Eimeria isolates were assessed by bivariate linear regression in GraphPad software.

\section{Results}

The averages of body weight gain (BWG), feed conversion ratio (FCR), and mortality on the farms included in the present study were $54.8 \mathrm{~g} /$ day (42.3-62.4), 2.0 (1.6$2.4)$, and $5.5 \%$ (2.5-11.9), respectively. The lowest BWG was recorded on farm "A", a small-size farm (42.3 g/day/ chicken in house 2 , flock 2), and the highest on farm "C", a medium-size farm (62.4 g/day/chicken in house 1, flock 1). The best FCR was observed on farm "G", a medium-size farm (1.6 in house 1, flock 1), and the lowest on farm " $\mathrm{A}$ " (2.4 in house 1, flock 2). The lowest percentage of mortality $(2.5-3.2 \%)$ was observed on farm " $\mathrm{C}$ ", while farms " $\mathrm{A}$ " (6.4-11.9\%) and "J" (6.6-10.6\%) had the highest mortality.

Al three categories of oocysts (AM, NTP, and BM) were found in 10 out of 11 flocks (Table 3), the most prevalent being AM (43.1\%) and NTP (44.4\%) groups. Prevalently on small-size farms was NTP group (50.6\%), while on medium-size farms was AM group (52\%). On large-size farms, those two groups were almost at the same level $(\mathrm{AM}=41.4 \%$; NTP $=44.6 \%)$.

The total lesion score (TLS) was significantly higher $(\mathrm{P}<0.05)$ on small $(\mathrm{TLS}=2.9)$ and large-size $(\mathrm{TLS}=2.5)$ farms than on medium size-farms (TLS $=0.9)($ Table 3$)$. Overall, the lesion score was the highest in the duodenum [1.8(0.4-4.0)] on small-size farms and in the caecum [1.5(0.0-3.0)] on large-size farms. The most virulent Eimeria spp. field isolates were found on farm "A", a smallsize farm (TLS $=5.4-6.1$ ), followed by isolates from farms "F" (small-size farm; TLS = 1.4-3.5) and "J", a large-size farm $($ TLS $=1.5-3.5)($ Table 2$)$. 
Body weight gain was associated with oocyst category $\mathrm{AM}$, lesion score in the duodenum, and coccidiostat used for chemoprophylaxis (Table 4). Feed conversion ratio was linked to the same parameters as BWG, minus chemoprophylaxis programme, plus total lesion score. The percentage of mortality was influenced by the lesion score in the caecum and total lesion score.

The total economic losses (Table 5) per 24 flocks of 18,000 chicks each were about $€ 37,948$.2, with an average of $€ 3,162.4$ per flock, and they were caused by mortality (34.8\%) and increased feed intake (65.2\%). Nevertheless, two farms out of six recorded profits. The highest economic losses were recorded on farm "A", a small-size farm (€57,441.0/4 flocks), where $18.6 \%, 44.2 \%$, and $37.2 \%$ of losses were caused by mortality, poor body weight gain, and increased feed intake, respectively. If on large-size farms the economic losses were due to mortality and FCR, on small and medium-size farms, BWG was also incriminated.

\section{Discussion}

The most problematic disease in the poultry industry worldwide is coccidiosis, mainly due to subclinical forms of diseases that interfere with body weight and feed conversion. It is estimated that $95.6-98.1 \%$ the economic losses in the commercial broiler industry are caused by coccidiosis (Williams, 1999; Bera et al., 2010).

Economic losses estimated by us for farms and flocks included in this study are underestimated because we did not estimate the cost with prophylaxis, with treatment, and the loss due to intercurrent diseases, which generally occur along with coccidiosis. We assumed the cost with prophylaxis as part of costs for feed; as for treatment, the farmers told us that they did not apply any treatment for coccidiosis in the investigated flocks.

Important economic losses were due to mortality (24.4\% on small-size farms and $43.9 \%$ on the large-size

Table 4 - Results of linear regression regarding the correlation between economic performance and oocyst categories and lesion score in the gut and chemoprophylaxis of coccidiosis

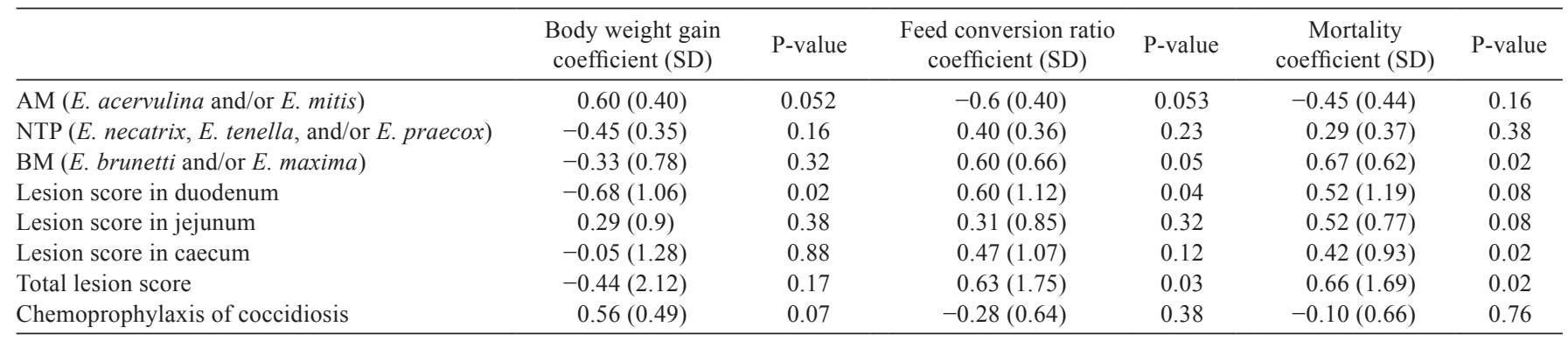

SD - standard deviation.

Table 5 - Economic losses caused by high mortality, poor body weight gain, and increases in feed conversion ratio

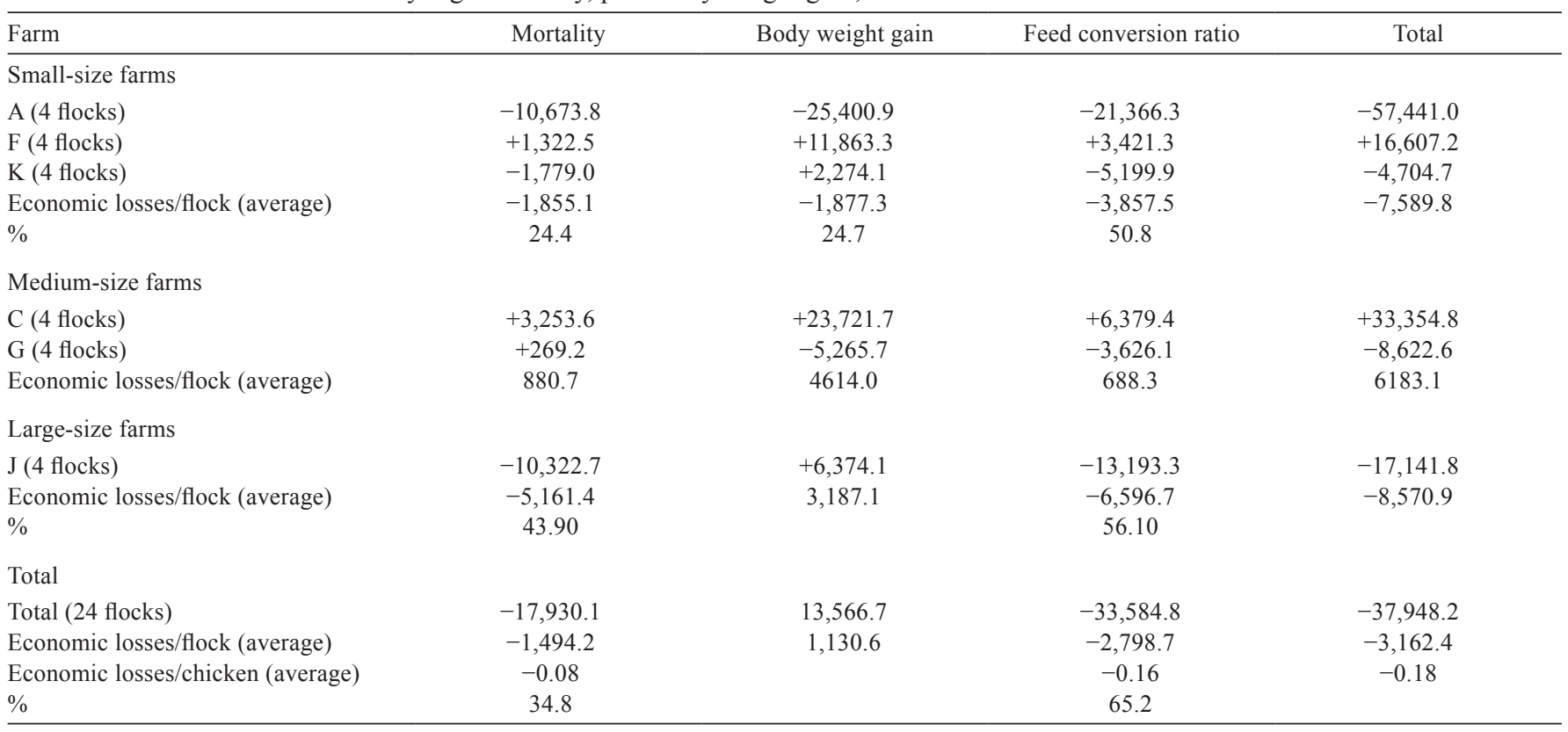


farm). These flocks presented high percentages of mortality, between 6.6 and 11.9. The causes of mortalities on a farm can be multiple, but in our cases we suspect they were caused by infection with E. tenella. On farms with high mortalities, the lesion score in the caecum after infection with 5,000 oocysts of Eimeria spp. was between 2 and 3, and the NTP oocyst category were predominant. Moreover, after statistical analysis, mortality was associated with lesion score in the caecum and total lesion score $(\mathrm{P}=0.02)$. E. tenella is one of the most pathogenetic species and causes bloody lesions, high morbidity, and mortality in chickens (Morris et al., 2007; Iacob and Duma, 2009). On these farms, there were possibly some outbreaks of coccidiosis. Outbreaks of coccidiosis may result from drug-resistance of parasites to the prophylactic drug used, accidental underdosing, overdilution of medicated feed with whole wheat, excessive drug withdrawal period, or reduced feed intake (Williams, 1999). Many other factors can cause outbreaks of coccidiosis, such as environmental and management factors; lack of use of overalls by visitors; poor hygienic status; personnel who might also be working on other farms; feeding and drinking systems, which are more difficult to clean; presence of other diseases on the farm; and Eimeria species found in the previous flock, which increases the risk of coccidiosis (Graat et al., 1998).

Otherwise, the increased FCR amounted to 50.8-65.2\% of the total losses due to coccidiosis, and it was statistically associated with oocyst category AM, score lesion in the duodenum, and total lesion score. In India, losses due to increased FCR are estimated at $23.74 \%$ from total cost (Bera et al., 2010).

In the world, economic losses due to subclinical coccidiosis are significant, estimated at more than US\$3 billion annually (Dalloul and Lillehoj, 2006). We estimated that the total economic losses due to coccidiosis for 2010 in Romania may have been at least $€ 28,971,818$.18. In comparison, in India, the cost for 2003-2004 was estimated at Rs1.089.170.162 ( €15,210,694.20) (Bera et al., 2010), and in the UK, for 1995, at about GB£38,588,795 ( €44,643,989.69) (Williams, 1999). In Ethiopia, average total losses were estimated at 898.8 and 5,301.8 Ethiopian Birr per farm on small- and large-scale farms, respectively (Kinung'hi et al., 2004). Generally, it is assumed that 70\% of the estimated costs are due to subclinical coccidiosis, by impact on weight gain and feed conversion rate (Gussem, 2007), and the economic importance of subclinical coccidiosis varies with composition of coccidial populations (Haug et al., 2008b).

Intensive chicken farming depends on specific prophylaxis of coccidiosis with in-feed anticoccidial drugs and live vaccines. Over time, coccidiostats have become less effective due to development of drug-resistance. Drugresistant Eimeria strains are responsible for subclinical coccidiosis and, subsequently, for impaired economical performance as body weight gain and feed conversion ratio (Shirzad et al., 2011). Drug-resistance was described recently on Romanian broiler farms to monensin, salynomicin, narasin, nicarbazin, robenidine, lasalocid, and diclazuril (Györke et al., 2011a; Györke et al., 2012). In this study, low body weight gain was associated also with coccidiostats (ionophores) used for chemoprophylaxis. It is well known that ionophores do not prevent replication of Eimeria completely (Chapman and Johnson, 1992) as chemicals do. To prevent drug resistance, rotation of coccidiostats and shuttle programmes are recommended. Small and medium farms in Romania do not have their own feed mill and in the most cases they cannot control the prophylaxis program (personal observation).

Investigated farms had mixed infections with all three categories of oocysts. In an epidemiological PCR study on Romanian broiler farms, E. acervulina, E. tenella, E. maxima, and E. praecox were identified (Györke et al., 2011b). The mixed infections are most likely more prevalent on small and medium farms due to poor management and biosecurity practises such as high stocking densities, reduced time between successive grow-outs (Lobago et al., 2005), microclimate, and workers (Kiani et al., 2007), but this was not our case; we found mixed infections in all three types of farms.

\section{Conclusions}

Statistical analysis regarding correlation between economic performance, oocyst category, and virulence of Eimeria isolates showed that epidemiological survey of broiler flocks during the grower period by classical methods can help the farmer to avoid important economic losses due to coccidiosis. As in other countries, the economic losses caused by coccidiosis in Romania are important, and they are caused mainly by mortality and poor feed conversion. Moreover, a good prophylaxis programm can reduce the economic impact of coccidiosis.

\section{Acknowledgments}

This work was supported by grants of the Romanian National Authority for Scientific Research, CNDI-UEFISCDI, project numbers $188 / 2010$ and $110 / 2012$. The paper is a full version of "Chemoprophylaxis of coccidiosis, performance and infection with Eimeria spp. in boiler farms from 
Romania" by Györke A., published in conference proceeding of XIX ${ }^{\text {th }}$ National Conference of Parasitology (16-17 December 2010, Bucharest, Romania).

\section{References}

Abbas, R. Z.; Iqbal, Z.; Sindhu, Z. D.; Kham, N. M. and Arshad, M. 2008. Identification of cross-resistance and multiple resistance in Eimeria tenella field isolates to commonly used anticoccidials in Pakistan. The Journal of Applied Poultry Research 17:361-368.

Bera, A. K.; Bhattacharya, D.; Pan, D.; Dhara, A.; Kumar, S. and Das, S. K. 2010. Evaluation of economic losses due to coccidiosis in poultry industry in India. Agricultural Economics Research 23:91-96.

Chapman, H. D. and Johnson, Z. B. 1992. Oocysts of Eimeria in the litter of broilers reared to eight weeks of age before and after withdrawal of lasalocid or salinomycin. Poultry Science $71: 1342-1347$

Chapman, H. D. 1997. Biochemical, genetic and applied aspects of drug resistance in Eimeria parasites of the fowl. Avian Pathology 26:221-244.

Dalloul, R. A. and Lillehoj, H. S. 2006. Poultry coccidiosis: recent advancements in control measures and vaccine development. Expert Review of Vaccines 5:143-163.

Graat, E. A.; Van Der Kooij, E. and Frankena, K. 1998. Quantifying risk factors of coccidiosis in broilers using on-farm data based on a veterinary practice. Preventive Veterinary Medicine 33:297-308.

Gussem, M. D. E. 2007. Coccidiosis in poultry: review on diagnosis, control, prevention and interaction with overall gut health. p.253-261. In: Proceedings of the 16th European Symposium on Poultry Nutrition. Strasbourg, France.

Györke, A.; Balea, A.; Mircean, V.; Iovu, A.; Achelăriței, D. and Cozma, V. 2011a. Drug resistance of Eimeria field isolates from commercial broiler flocks in Romania: preliminary results. Bulletin USAMV, Veterinary Medicine 68:311.

Györke, A.; Mircean, V. and Cozma, V. 2011b. Identification of Eimeria species in chickens from commercial flocks. p.149-151. In: Proceeding of the 11th National Congress of Veterinary Medicine. Bucharest, Romania.

Györke, A.; Pop, L.; Balea, A. and Paştiu, A. 2012. Drug-resistance to anticoccidials of Eimeria spp. field isoaltes collected in 2010 from broiler chickens farms in Romania. p.84. In: Proceedings of the 1st Apicomplexa in Farm Animals. Lisbon, Portugal.

Hamidinejat, H.; Shapouri, M. S.; Mayahi, M. and Borujeni, M. P. 2010. Characterization of Eimeria species in commercial broilers by PCR based on ITS1 regions of rDNA. Iranian Journal of Parasitology 5:48-54.

Harfoush, M. A.; Hegazy, A. M.; Soliman, A. H. and Amer, S. 2010. Drug resistance evaluation of some commonly used anti-coccidial drugs in broiler chickens. Journal of the Egyptian Society of Parasitology 40:337-348.

Haug, A.; Gjevre, A. G.; Thebo, P.; Mattsson, J. G. and Kaldhusdal, M. 2008a. Coccidial infections in commercial broilers: epidemiological aspects and comparison of Eimeria species identification by morphometric and polymerase chain reaction techniques. Avian Pathology 37:161-170.

Haug, A.; Gjevre, A. G.; Skjerve, E. and Kaldhusdal, M. 2008b. A survey of the economic impact of subclinical Eimeria infections in broiler chickens in Norway. Avian Pathology 37:333-341.

Hemsley, L. A. 1964. Experiences of coccidiosis in young chickens fed a coccidiostat with a particular reference to the incidence of coccidiosis in broiler chickens in the south of England 1961-1964. Veterinary Record 76:1432-1436.

Iacob, O. C. and Duma, V. 2009. Clinical paraclinical and morphopathological aspects in cecal eimeriosis of broilers. Scientia Parasitologica 10:43-50.

Jenkins, M.; Klopp, S.; Ritter, D.; Miska, K. and Fetterer, R. 2010. Comparison of Eimeria species distribution and salinomycin resistance in commercial broiler operations utilizing different coccidiosis control strategies. Avian Diseases 54:1002-1006.

Johnson, J. and Reid, W. M. 1970. Anticoccidial drugs: lesion scoring techniques in battery and floorpen experiments with chickens. Experimental Parasitology 28:30-36.

Kawazoe, U. and Fabio, J. D. 1994. Resistance to diclazuril in field isolates of Eimeria species obtained from commercial broiler flocks in Brazil. Avian Pathology 23:305-311.

Kiani, R.; Rasadi, M. and Mohammadian, M. N. 2007. Sources and routes of introduction of Eimeria oocysts into broiler chick's houses. International Journal of Poultry Science 6:925-927.

Kinung'hi, S. M.; Tilahun, G.; Hafez, H. M.; Woldemeskel, M.; Kyule, M.; Grainer, M. and Baumann, M. P. O. 2004. Assessment of economic impact caused by poultry coccidiosis in small and large scale poultry farms in Debre Zeit, Ethiopia. International Journal of Poultry Science 3:715-718.

Lobago, F.; Worku, N. and Wossene, A. 2005. Study on coccidiosis in Kombolcha Poultry Farm, Ethiopia. Tropical Animal Health and Production 37:245-251.

Long, P. L. and Reid, W. M. 1982. A guide for the diagnosis of coccidiosis in chickens. Research report 404. 17p. The University of Georgia, College of Agriculture, Experiment Stations, Athens, GA, Greece.

Morris, G. M.; Woods, W. G.; Richards, D. G. and Gasser, R. B. 2007. Investigating a persistent coccidiosis problem on a commercial broiler-breeder farm utilising PCR-coupled capillary electrophoresis. Parasitology Research 101:583-589

Ogedengbe, J. D.; Hunter, D. B. and Barta, J. R. 2011. Molecular identification of Eimeria species infecting market-age meat chickens in commercial flocks in Ontario. Veterinary Parasitology 178:350-354.

Peek, H. W. and Landman, W. J. 2003. Resistance to anticoccidial drugs of Dutch avian Eimeria spp. field isolates originating from 1996, 1999 and 2001. Avian Pathology 32:391-401.

Peek, H. W. and Landman, W. J. M. 2011. Coccidiosis in poultry: anticoccidial products, vaccines and other prevention strategies. Veterinary Quarterly 31:143-161.

Peeters, J. E.; Derijcke, J.; Verlinden, M. and Wyffels, L. 1994. Sensitivity of avian Eimeria spp. to seven chemical and five ionophore anticoccidials in five Belgian integrated broiler operations. Avian Diseases 38:483-493.

Shirley, M. W. 1986. New methods for the identification of species and strains of Eimeria. p:13-35. In: Research in avian coccidiosis. McDougald, L. R.; Joyner, L. P. and Long, P. L., eds. Athens, Greece.

Shirley, M. V. 1995. Eimeria species and strains. p:1-25. In: Guidelines on techniques in coccidiosis research. Eckert, J.; Braun, R.; Shirley, M. W. and Coudert, P., eds. Luxembourg, Louxemburg.

Shirzad, M. R.; Seifi, S.; Gheisari, H. R.; Hachesoo, B. A.; Habibi, H. and Bujmehrani, H. 2011. Prevalence and risk factors for subclinical coccidiosis in broiler chicken farms in Mazandaran province, Iran. Tropical Animal Health and Production 43:1601-1604.

Stephen, B.; Rommel, M.; Daugschies, A. and Haberkorn, A. 1997. Studies of resistance to anticoccidials in Eimeria field isolates and pure Eimeria strains. Veterinary Parasitology 69:19-29. 
Sun, X. M.; Pang, W.; Jia, T; Yan, W. C.; He, G.; Hao, L. L.; Bentué, M. and Suo, X. 2009. Prevalence of Eimeria species in broilers with subclinical signs from fifty farms. Avian Diseases 53:301-305.

Williams, R. B. 1999. A compartmentalised model for the estimation of the cost of coccidiosis to the world's chicken production industry. International Journal for Parasitology 29:1209-1229.

Williams, R. B. 2002. Anticoccidial vaccines for broiler chickens: pathways to success. Avian Pathology 31:317-353.
Williams, R. B. 2006. Tracing the emergence of drug-resistance in coccidia (Eimeria spp.) of commercial broiler flocks medicated with decoquinate for the first time in the United Kingdom. Veterinary Parasitology 135:1-14.

Zhang, J. J.; Wang, L. X.; Ruan, W. K. and An, A. J. 2013. Investigation into the prevalence of coccidiosis and maduramycin drug resistance in chickens in China. Veterinary Parasitology 191:29-34. 